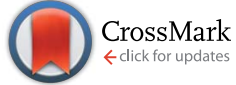

Cite this: J. Anal. At. Spectrom., 2015, 30, 1322

Received 18th December 2014 Accepted 20th February 2015

DOI: $10.1039 / c 4 j a 00484 a$

www.rsc.org/jaas

\section{Lead isotopic analysis of Antarctic snow using multi-collector ICP-mass spectrometry}

\begin{abstract}
Andrea Bazzano, ${ }^{\text {ab }}$ Kris Latruwe, ${ }^{b}$ Marco Grotti ${ }^{a}$ and Frank Vanhaecke ${ }^{\star b}$
Reliable determination of $\mathrm{Pb}$ isotope ratios in Antarctic snow is challenging because of the low analyte concentration and the low volume of sample typically available. In this work, a combination of a total sample consumption introduction system (the torch-integrated sample introduction system, TISIS) with multi-collector ICP-mass spectrometry (MC-ICP-MS) was used for this purpose. With this instrumental setup, accurate and precise determination of $\mathrm{Pb}$ isotope ratios was possible at concentrations as low as $0.5 \mathrm{ng} \mathrm{mL}$, while using $0.2 \mathrm{~mL}$ of solution only (total amount of $\mathrm{Pb}: 100 \mathrm{pg}$ ). At $10 \mathrm{ng} \mathrm{mL}^{-1}$, the repeatability for the ${ }^{207} \mathrm{~Pb} /{ }^{206} \mathrm{~Pb}$ ratio was $0.16 \%$ RSD. The concentration range was further extended downwards by using 100-fold analyte element preconcentration via freeze-drying of $20 \mathrm{~g}$ of snow. The $\mathrm{Pb}$ concentration in procedural blanks was $0.5 \pm 0.3 \mathrm{pg} \mathrm{g}^{-1}$, enabling the determination of $\mathrm{Pb}$ isotope ratios in snow samples containing down to $5 \mathrm{pg} \mathrm{g}^{-1}$ of $\mathrm{Pb}$. After development and validation, the procedure was applied to snow samples collected at Dome C (East Antarctic Plateau) on a monthly basis during the 2006 and 2010 campaigns. The method developed was able to reveal a seasonal variation in the $\mathrm{Pb}$ isotope ratios occurring during 2006 and strong inter-annual variation between the two campaigns.
\end{abstract}

\section{Introduction}

The determination of $\mathrm{Pb}$ isotope ratios in the Antarctic and Greenland snow and ice caps can provide valuable information on the geographical sources of both natural and anthropogenic atmospheric inputs, the relative contributions of these sources over time and the corresponding transport routes. ${ }^{1-3}$ The accurate measurement of these isotope ratios can, however, be quite challenging. Indeed, the $\mathrm{Pb}$ concentration in polar snow and ice is extremely low, typically at or below the $\mathrm{pg} \mathrm{g}^{-1}$ level, ${ }^{4}$ therefore requiring the application of ultraclean procedures for sampling, sample storage and treatment, as well as very high instrument sensitivities.

Isotope dilution-thermal ionisation mass spectrometry (IDTIMS) is capable of the simultaneous determination of the concentration of $\mathrm{Pb}$ and its isotopic composition and therefore appears to be the method of choice for the analysis of snow and ice samples of limited size., ${ }^{5,6}$ Multi-collector inductively coupled plasma-mass spectrometry (MC-ICP-MS) can be considered a strong competitor of TIMS for many applications, ${ }^{7}$ but so far, it has not been employed for the determination of $\mathrm{Pb}$ isotope ratios in snow samples from polar areas. For achieving an adequate isotope ratio precision, a relatively high target element concentration is required due to the low analyte transport efficiency

${ }^{a}$ Department of Chemistry and Industrial Chemistry, University of Genoa, Via Dodecaneso 31, 16146 Genoa, Italy

${ }^{b}$ Department of Analytical Chemistry, Ghent University, Krijgslaan 281-S12, 9000 Ghent, Belgium. E-mail: Frank.Vanhaecke@UGent.be from the sample solution to the detectors and the modest sensitivity of the Faraday cups used for ion monitoring. For many sample types, this problem can be circumvented via an analyte pre-concentration step, but this approach requires relatively large sample amounts, thus reducing the spatial/temporal resolution of the information provided in the specific case of $\mathrm{Pb}$ isotopic analysis of snow samples. A way to increase the instrumental sensitivity, while adhering to a low sample consumption, is the use of a so-called "total consumption" sample introduction system. Among these total consumption devices, the torch-integrated sample introduction system (TISIS) ${ }^{\mathbf{8}, 9}$ was already proven capable of efficient introduction of microsamples into an ICP source, in both atomic emission (ICP-AES) ${ }^{\mathbf{1 0 , 1 1}}$ and mass spectrometry (ICP-MS). ${ }^{12,13}$ In its final design, the TISIS consists of a single-pass high-temperature evaporation chamber, with a lateral port to introduce a sheathing gas stream, in a location close to the aerosol production point. In this way, the aerosol solvent evaporation was enhanced and the impact of droplets against the cavity walls reduced.

Paredes et al. investigated the performance of a TISIS coupled with MC-ICP-MS for the determination of $\mathrm{Pb}^{\mathbf{1 4}}$ and $\mathrm{Sr}^{\mathbf{1 5}, 16}$ isotope ratios. Accurate data were obtained at a very low sample uptake rate $\left(5-30 \mu \mathrm{L} \min ^{-1}\right)$ and at a total sample consumption of less than $0.3 \mathrm{~mL}$ of solution. However, in these works, relatively high element concentrations were considered, resulting in a signal strength of about $1 \mathrm{~V}$ for the most abundant isotope monitored. The low concentration levels of $\mathrm{Pb}$ in snow from remote areas brings us far away from these ideal conditions. 
In this work, snow samples were first submitted to analyte preconcentration, based on sample volume reduction by freezedrying. ${ }^{17}$ The solutions thus obtained were introduced into an MC-ICP-MS instrument for Pb isotopic analysis using a TISIS. This analytical protocol was optimised, characterised in terms of precision and accuracy at ultra-trace concentration level, and, finally, applied to the analysis of recent snow collected from Antarctica during two year-round expeditions.

\section{Materials and methods}

All solutions were prepared with ultrapure water (resistivity $\geq$ 18.2 $\mathrm{M} \Omega \mathrm{cm}$ ), obtained from a Milli-Q Element water purification system (Millipore, Mollsheim, France). Suprapur® 65\% $\mathrm{HNO}_{3}$ from Merck (Darmstadt, Germany) was used for the cleaning of materials, while Trace Select ${ }^{\circledR}$ Ultra $65 \% \mathrm{HNO}_{3}$ from Sigma-Aldrich (St. Louis, MO, USA) was used for the final stage of the cleaning procedure. Optima ${ }^{\mathrm{TM}} \mathrm{HNO}_{3}$ from Fisher Chemicals (Waltham, MA, USA) was used for the preparation of standards and samples.

All work, except for the pre-concentration procedure, was carried out in a metal-free class-10 clean lab facility at Ghent University. The pre-concentration procedure was accomplished in a class-100 laminar flow area at the University of Genoa.

\subsection{Standard reference materials}

Isotopic reference materials for Pb (NIST SRM 981) and Tl (NIST SRM 997), acquired from the National Institute for Standards and technology (NIST, Gaithersburg, MD, USA), were used for correction for the bias introduced by instrumental mass

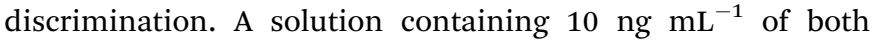
elements in $0.05 \%$ ultrapure $\mathrm{HNO}_{3}$ matrix was prepared for that purpose. The values used for the mass bias correction were ${ }^{207} \mathrm{~Pb} /{ }^{206} \mathrm{~Pb}=0.91464 \pm 0.00033 ;{ }^{208} \mathrm{~Pb} /{ }^{206} \mathrm{~Pb}=2.1681 \pm$ $0.0008 ;{ }^{208} \mathrm{~Pb} /{ }^{207} \mathrm{~Pb}=2.3704 \pm 0.00049$ and ${ }^{203} \mathrm{Tl} /{ }^{205} \mathrm{Tl}=$ $0.418922 \pm 0.00028$, as reported on the certificates released by NIST.

A $10 \mathrm{ng} \mathrm{mL} \mathrm{m}^{-1}$ in-house isotopic standard was prepared by serial dilution of a commercially available $1 \mathrm{mg} \mathrm{mL}{ }^{-1}$ stock solution (Inorganic Ventures, Christiansburg, VD, USA; lot G2$\mathrm{PB} 03044)$ and is further referred to as "A\&MS-Pb". Lead isotope ratios for this solution are ${ }^{207} \mathrm{~Pb} /{ }^{206} \mathrm{~Pb}=0.90413 \pm 0.00002$, ${ }^{208} \mathrm{~Pb} /{ }^{206} \mathrm{~Pb}=2.15331 \pm 0.00003$ and ${ }^{208} \mathrm{~Pb} /{ }^{207} \mathrm{~Pb}=2.38167 \pm$ 0.00003 (average $\pm 95 \%$ confidence interval; $n=15$; determined at $100 \mathrm{ng} \mathrm{Pb} \mathrm{mL} \mathrm{mL}^{-1}$ using a conventional sample introduction system working at sample uptake rate of $200 \mu \mathrm{L} \mathrm{min}{ }^{-1}$ ).

\subsection{Instrumentation and measurements}

Lead isotope ratios were measured using a Thermo Scientific (Bremen, Germany) Neptune MC-ICP-MS instrument, operating at low mass resolution. The solutions were introduced into the plasma by means of a PFA nebuliser, operating in self-aspira-

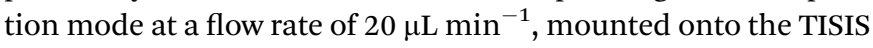
chamber. The system required $0.2 \mathrm{~mL}$ of solution for each analysis. The instrument settings and data acquisition parameters are summarized in Table 1.

Table 1 Thermo Scientific Neptune instrument settings and data acquisition parameters

Instrumental parameters

Sample uptake rate $\left(\mu \mathrm{L} \min ^{-1}\right)$

Plasma gas flow rate $\left(\mathrm{L} \mathrm{min}^{-1}\right)$

Auxiliary gas flow rate $\left(\mathrm{L} \mathrm{min}^{-1}\right)$

Nebuliser gas flow rate $\left(\mathrm{L} \mathrm{min}^{-1}\right)$

Sheating gas flow rate $\left(\mathrm{L} \mathrm{min}^{-1}\right)^{a}$

Temperature of the chamber $\left({ }^{\circ} \mathrm{C}\right)^{a}$

RF power (W)

Sampling cone

Skimmer

Lens settings

Resolution mode
20

15

0.90

0.72

0.35

150

1200

$\mathrm{Ni} ; 1.1 \mathrm{~mm} \emptyset$ orifice

$\mathrm{Ni}$; H-type; $0.8 \mathrm{~mm} \varnothing$ orifice

Optimised for maximum $\mathrm{Pb}$ signal intensity Low

Data acquisition parameters

Scan type

Number of blocks

Number of cycles/block

Integration time $(\mathrm{s})$

Magnet settling time (s)

Idle time (s)

Cup configuration ${ }^{b}$

Resistivity of the pre-amplifier
Static; multi-collection

7

6

8.4

0

L3: ${ }^{202} \mathrm{Hg}$; L2: ${ }^{203} \mathrm{Tl}$; L1: ${ }^{204} \mathrm{~Pb},{ }^{204} \mathrm{Hg}$; C:

${ }^{205} \mathrm{Tl}$; H1: ${ }^{206} \mathrm{~Pb}$; H2: ${ }^{207} \mathrm{~Pb}$; H3: ${ }^{208} \mathrm{~Pb}$

C, L1, L2, L3: $10^{11} \Omega$; H1, H2, H3: $10^{12} \Omega$

${ }^{a}$ Parameters of the TISIS chamber. ${ }^{b}$ As a result of the low isotopic abundance of ${ }^{204} \mathrm{~Pb}$ and the spectral overlap from ${ }^{204} \mathrm{Hg}$, $\mathrm{Pb}$ isotope ratios including this $\mathrm{Pb}$ nuclide were not considered. 
All sample and standard solutions were prepared in $0.05 \%$ ultrapure $\mathrm{HNO}_{3}$ doped with $10 \mathrm{ng} \mathrm{mL} \mathrm{m}^{-1}$ of Tl (NIST SRM 997) and the correction for the bias introduced by instrumental mass discrimination was performed offline using the method proposed by Woodhead et al. ${ }^{18}$ and further refined by Baxter et $a l .{ }^{19}$ With this method, a regression line in $\ln -\ln$ space is determined by measuring both the isotope ratio for Tl (NIST SRM 997) and that selected for Pb (NIST SRM 981) in a series of standard solutions. Based on the regression line thus obtained and the Tl isotope ratio measured for NIST SRM $997 \mathrm{Tl}$, admixed to the sample, the mass bias is corrected for.

The A\&MS-Pb solution was analysed as a quality control sample every five samples, whereas a full procedural blank was analysed for every analytical batch.

\subsection{Sample collection and analysis}

Antarctic snow samples were collected with a monthly resolution at Dome C (East Antarctic Plateau) during the 2006 and 2010 campaigns. In order to prevent contamination during sampling, the scientists taking the samples wore a clean room suit and approached the sampling site upwind. The samples were collected in acid-cleaned $50 \mathrm{~mL}$ PP graduated tubes (Kartell, Milan, Italy), sealed inside double polyethylene bags and stored at $-20{ }^{\circ} \mathrm{C}$ until analysis. Following a previously developed procedure, ${ }^{20}$ samples were first allowed to melt in their closed tubes. Subsequently, $20 \mathrm{~g}$ aliquots were transferred into acid-cleaned $50 \mathrm{~mL}$ PP graduated tubes, acidified with $100 \mu \mathrm{L}$ of $\mathrm{HNO}_{3}$ and refrozen. Then, the samples were freeze-dried, redissolved in $0.2 \mathrm{~mL}$ of $0.05 \% \mathrm{HNO}_{3}$ solution containing $10 \mathrm{ng} \mathrm{\textrm {mL } ^ { - 1 }}$ of Tl (NIST SRM 997) and analysed using MC-ICP-MS.

\section{Results and discussion}

\subsection{Sensitivity and stability of the signal}

Instrumental sensitivity strongly depended on the combination of both nebuliser and sheathing gas flow rate, resulting in a behaviour similar to that described earlier for different instru-

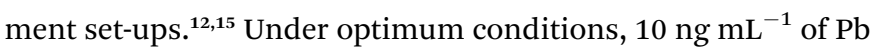
(NIST SRM 981) gave rise to a signal of about $0.4 \mathrm{~V}$ for ${ }^{208} \mathrm{~Pb}$ with a variation $<2 \%$ RSD over a period of more than six hours of analysis.

The signal produced by the reagents blank $(0.05 \%$ of ultrapure $\mathrm{HNO}_{3}$ ) was about $10^{-5} \mathrm{~V}$ for ${ }^{208} \mathrm{~Pb}$ and was stable during approximately six hours of analysis. After this period of time, signal spikes usually started to appear, necessitating the analysis to be stopped. In such an event, the TISIS chamber was thoroughly cleaned by immersion in a bath of hot $\mathrm{HNO}_{3}$ (about $10 \% \mathrm{v} / \mathrm{v}$ ) for several hours. This phenomenon was already described by Paredes et al. ${ }^{\mathbf{1 4}}$ and is likely due to the re-nebulisation of dry analyte particles from the nebuliser tip and the spray chamber walls.

\subsection{Precision and repeatability}

Precision is an important parameter for all analytical methods dealing with the measurement of isotope ratios, since it directly influences the uncertainties associated to each value, and thus, the capability to obtain a meaningful interpretation of the results.

The repeatability or internal precision (RSD for 42 successive measurements) was studied in a concentration range from 0.5 to $10 \mathrm{ng} \mathrm{mL} \mathrm{mL}^{-1}$ of $\mathrm{Pb}$ (NIST SRM 981), equivalent to a total $\mathrm{Pb}$ amount from 0.1 to 2 ng. In Fig. 1, the RSD for the ${ }^{207} \mathrm{~Pb} /{ }^{206} \mathrm{~Pb}$ ratio is reported, showing values below $1.5 \%$ in the entire concentration range studied. At $10 \mathrm{ng} \mathrm{mL} \mathrm{m}^{-1} \mathrm{of} \mathrm{Pb}$, the RSD was $0.16 \pm 0.03 \%$ (average $\pm 95 \%$ confidence interval). This value is more than an order of magnitude better than that reported using the same sample introduction system, but using a quadrupole-based ICP-MS instrument with ammonia as a damping gas for smoothing the fluctuations of the ion beam intensity for $\mathrm{Pb}$ isotope ratio measurements. ${ }^{17}$

The intermediate or external precision was assessed by measuring the ${ }^{207} \mathrm{~Pb} /{ }^{206} \mathrm{~Pb}$ ratio in a solution with $10 \mathrm{ng} \mathrm{mL} \mathrm{m}^{-1}$ of $\mathrm{Pb}$ (NIST SRM 981) over a period of more than three months and was $0.11 \%$ o $(0.91465 \pm 0.00005, n=73)$ when expressed as twice the relative standard deviation of the ratios (not the standard error of the mean). This result is very similar to that obtained by Cocherie et al. ${ }^{21}$ who reported a value of $0.1 \%$ using a similar MC-ICP-MS instrument and a sample uptake rate of $50 \mu \mathrm{L} \mathrm{min}{ }^{-1}$. Similar values have also been reported by Kuritani et $a .^{22}$ $(0.13 \%)$ and Amelin et al. ${ }^{23}(0.07 \%)$ for isotopic analysis of absolute amounts of $\mathrm{Pb}$ of 1 and $2 \mathrm{ng}$ by TIMS and double-spike TIMS, respectively. On the other hand, Makishima et al. ${ }^{24}$ reported a reproducibility down to $0.03 \%$ in the isotopic anal-

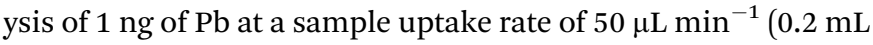
total sample consumption) when using an Aridus II aerosol desolvation system and a Neptune MC-ICP-MS instrument equipped with a Jet-type skimmer cone (also termed X-type), characterised by enhanced transport efficiency. Finally, Thirlwall $^{25}$ reported an external precision of 0.06-0.18\% (2 SD) for isotopic analysis of $\sim 7 \mathrm{ng}$ of $\mathrm{Pb}$ using double-spike MC-ICP-MS and the Aridus desolvation system.

When reducing the $\mathrm{Pb}$ concentration to $0.5 \mathrm{ng} \mathrm{mL} \mathrm{m}^{-1}$, the intermediate precision deteriorated to $0.31 \%$ o $(0.91438 \pm$ $0.00028, n=3$ ) for the ${ }^{207} \mathrm{~Pb} /{ }^{206} \mathrm{~Pb}$ ratio.

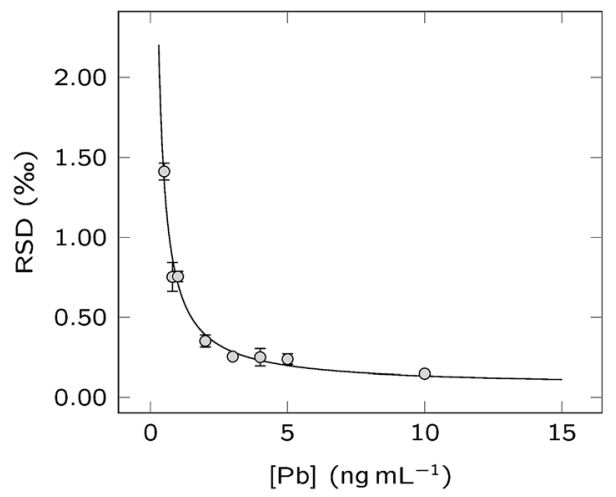

Fig. 1 Variation of the ${ }^{207} \mathrm{~Pb} /{ }^{206} \mathrm{~Pb}$ isotope ratio repeatability (internal precision) with the $\mathrm{Pb}$ concentration. The solid line is the best-fitting curve through the experimental data and the error bars represent the standard deviation of the average repeatability $(n=3)$. 


\subsection{Validation of the measurement results}

The validity of the $\mathrm{Pb}$ isotope ratios determined via the newly developed method was evaluated by analysing the in-house A\&MS-Pb standard, previously characterized using the standard MC-ICP-MS procedure. The average biases and their accompanying 95\% confidence intervals for ${ }^{207} \mathrm{~Pb} /{ }^{206} \mathrm{~Pb}$ measurement were $0.06 \pm 0.03 \%(n=25)$ and $0.25 \pm 0.08 \%(n=3)$ at 10 and $0.5 \mathrm{ng} \mathrm{mL}^{-1}$, respectively. The reported biases are within the range defined by the intermediate precision calculated in the previous section, thus the method provides accurate lead isotope ratios over the range of $\mathrm{Pb}$ concentration from 0.5 to $10 \mathrm{ng} \mathrm{mL} \mathrm{m}^{-1}$.

\subsection{Procedural blanks}

The instrumental performance reported on so far deemed suitable for the accurate determination of ${ }^{207} \mathrm{~Pb} /{ }^{206} \mathrm{~Pb}$, ${ }^{208} \mathrm{~Pb} /{ }^{206} \mathrm{~Pb}$ and ${ }^{208} \mathrm{~Pb} /{ }^{207} \mathrm{~Pb}$ ratios at concentration levels from 0.5 to $10 \mathrm{ng} \mathrm{mL}{ }^{-1}$, using $0.2 \mathrm{~mL}$ of solution only and therefore, requiring 0.1 to $2 \mathrm{ng}$ of total $\mathrm{Pb}$ only. In order to further decrease the lowest concentration feasible, a simple pre-concentration procedure relying on freeze-drying was used for sample pretreatment. The corresponding blank contribution was estimated on the basis of 5 synthetic samples, obtained by pouring $20 \mathrm{~g}$ of ultrapure water (the same mass as for the snow samples) in acid-cleaned tubes that were subsequently submitted to the entire analytical procedure.

The $\mathrm{Pb}$ concentration was estimated by comparing the $\mathrm{Pb}$ intensity observed for the blanks to that of the closest standards (NIST SRM 981 at $10 \mathrm{ng} \mathrm{mL}{ }^{-1}$ ), resulting in a concentration of $0.5 \pm 0.3 \mathrm{pg} \mathrm{g}^{-1}$ (or an absolute amount of $10 \pm 6 \mathrm{pg} \mathrm{Pb}$ ) and a $\mathrm{Pb}$ isotopic composition characterized by ${ }^{207} \mathrm{~Pb} /{ }^{206} \mathrm{~Pb}=0.868 \pm$ 0.008 and ${ }^{208} \mathrm{~Pb} /{ }^{206} \mathrm{~Pb}=2.103 \pm 0.020$. Taking these results into account, the blank can induce variations in the isotopic composition ranging from 0.1 to $0.2 \%$ in snow samples with a $\mathrm{Pb}$ concentration of $5 \mathrm{pg} \mathrm{g}^{-1}$, the lowest $\mathrm{Pb}$ concentration encountered in the snow samples analyzed. A bias of this magnitude is relatively small compared to the natural variation in the isotopic composition of $\mathrm{Pb}$ as measured in Antarctic snow and ice. ${ }^{2,26}$

\subsection{Uncertainty estimation}

In order to discriminate different isotope ratios and hence, apply the results of isotopic analysis to environmental studies, a realistic estimation of the uncertainty is needed. The total uncertainty was calculated by combining the different single contributions, according to the GUM guidelines. ${ }^{27}$ The contributions considered are related to (i) the instrumental precision in measuring the $\mathrm{Pb}$ isotope ratios in the samples $\left(r_{\mathrm{x}}\right)$, (ii) the precision in measuring the $\mathrm{Tl}$ isotope ratio $\left(r_{\mathrm{s}}\right)$, (iii) the error associated to the reference values for NIST SRM $981\left(R_{\mathrm{c}}\right)$, and (iv) the error due to the blank subtraction $\left(r_{\mathrm{b}}\right)$.

The relative contributions for the first three effects were estimated and propagated according to eqn (1), previously reported by Baxter et al., ${ }^{19}$ and based on the assumption that the input quantities are not correlated

$$
\begin{aligned}
\frac{u_{c}{ }^{2}\left(R_{\mathrm{x}, \text { corr }}\right)}{R_{\mathrm{x}, \text { corr }}{ }^{2}}= & \frac{s_{\mathrm{m}}{ }^{2}\left(r_{\mathrm{x}}\right)}{r_{\mathrm{x}}{ }^{2}}+\frac{s_{\mathrm{m}}{ }^{2}\left(r_{\mathrm{s}}\right)}{r_{\mathrm{s}}{ }^{2}} b^{2}+s_{\mathrm{m}}{ }^{2}(b)\left[\ln \left(\frac{r_{\mathrm{s}}}{\rho_{\mathrm{s}, \mathrm{SRM}}}\right)\right]^{2} \\
& +\frac{s_{\mathrm{m}}{ }^{2}\left(R_{\mathrm{c}}\right)}{R_{\mathrm{c}}{ }^{2}}
\end{aligned}
$$

here $b$ is the estimated slope of the regression line used for the mass-bias correction, $\rho$ denotes the means of the uncorrected ratios for the analyte and $s_{\mathrm{m}}{ }^{2}\left(r_{\mathrm{i}}\right)$ is the standard error of the mean for a generic ratio $r_{i}$ measured within the blocks. Due to the low influence of $s_{\mathrm{m}}{ }^{2}(b)$ ( $<1 \%$ of the total uncertainty budget), it was merged with $s_{\mathrm{m}}{ }^{2}\left(r_{\mathrm{s}}\right)$.

The relative contribution from the blank was estimated as the difference in the combined uncertainty calculated before and after the subtraction of the intensity of the blank.

Finally, the expanded uncertainty was calculated by multiplying the combined uncertainty, $u_{\mathrm{c}}\left(R_{\mathrm{x}, \mathrm{corr}}\right)$ with a coverage factor $k=2$.

In Fig. 2, the different contributions to the combined uncertainty are visualized at concentrations of 5, 23 and

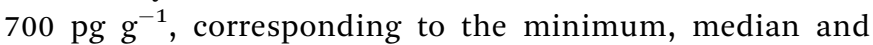
maximum concentration found in the Antarctic snow samples analysed (see next section). In the first case, the major contributions came from the instrumental precision (57\%) and the blank (37\%), whereas the contribution from the uncertainty on the NIST SRM 981 certified value accounted for $6 \%$ only. On the other hand, at higher concentrations, $55-77 \%$ of the uncertainty is attributed to the uncertainty of the certified value, $20-41 \%$ is stemming from the $\mathrm{Pb}$ isotope ratio measurement precision, while the contribution to the uncertainty coming from the blank is lower than $2 \%$.
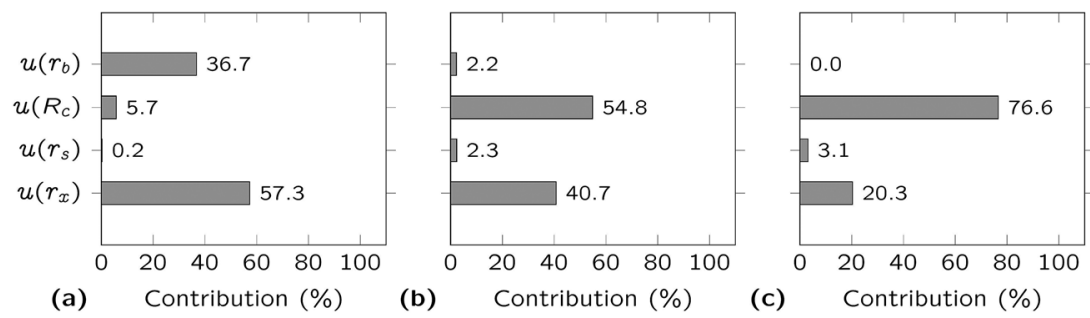

Fig. 2 Contribution to the combined uncertainty of the measurement precision for the $\mathrm{Pb}$ isotope ratio in the sample $\left(r_{x}\right)$; the measurement precision for the Tl isotope ratio $\left(r_{\mathrm{s}}\right)$; the uncertainty associated to the certified value for NIST SRM $981\left(R_{\mathrm{c}}\right)$, and the blank $\left(r_{\mathrm{b}}\right)$. In sub-figures (a), (b) and (c) samples with a $\mathrm{Pb}$ concentration of 5, 23 and $700 \mathrm{pg} \mathrm{g}^{-1}$ are considered. 
Despite the increased influence of the blank at low concentrations, it did not appear to be the main effect in the range of concentrations from 5 to $700 \mathrm{pg} \mathrm{g}^{-1}$. The contribution from the uncertainty on the certified value was found to become dominant at concentrations above $20 \mathrm{pg} \mathrm{g}^{-1}$. A better precision can be achieved when using the literature data obtained for NIST SRM 981 by double spike techniques ${ }^{24,25,28,29}$ instead of the NIST certified values, but it could be argued that the confidence in these data cannot be as high as in the certified values. At $\mathrm{Pb}$ concentrations below $20 \mathrm{pg} \mathrm{g}^{-1}$, the uncertainty associated to the $\mathrm{Pb}$ isotope ratios can be reduced by up to $40 \%$ by increasing the instrument sensitivity. Additionally, lowering the blank level could result in reducing the uncertainty by more than $20 \%$ for samples with $\mathrm{Pb}$ concentrations below $10 \mathrm{pg} \mathrm{g}^{-1}$.

\subsection{Lead isotope ratios measured in recent Antarctic snow with monthly resolution}

${ }^{207} \mathrm{~Pb} /{ }^{206} \mathrm{~Pb},{ }^{208} \mathrm{~Pb} /{ }^{206} \mathrm{~Pb}$ and ${ }^{208} \mathrm{~Pb} /{ }^{207} \mathrm{~Pb}$ isotopes ratios were determined in recent snow samples, collected on a monthly basis during the 2006 and 2010 campaigns. Snow from inland Antarctica is a very simple matrix, not requiring any $\mathrm{Pb}$ isolation step. Indeed, the most abundant species is $\mathrm{Na}^{+}$, the concentration of which is typically below $100 \mathrm{ng} \mathrm{mL}{ }^{-1} \cdot{ }^{30,31}$ Therefore, the $\mathrm{Na}^{+}$concentration after the sample preparation step $(<10 \mu \mathrm{g}$ $\left.\mathrm{mL}^{-1}\right)$ was well below the concentration $\left(400 \mu \mathrm{g} \mathrm{mL} L^{-1}\right)$ for which Cocherie et al. ${ }^{21}$ reported a $0.09 \%$ bias in the MC-ICP-MS ${ }^{207} \mathrm{~Pb} /{ }^{206} \mathrm{~Pb}$ measurement.

The analytical procedure required $20 \mathrm{~g}$ of snow and about 10 minutes for each isotope ratio measurement. The $\mathrm{Pb}$ concentration was estimated by comparison of the $\mathrm{Pb}$ intensity observed for the sample to that of the closest standards (NIST SRM 981 at $\left.10 \mathrm{ng} \mathrm{mL}^{-1}\right)$ and it ranged from 5 to $707 \mathrm{pg} \mathrm{g}^{-1}(0.1$ to $14.1 \mathrm{ng}$ of $\mathrm{Pb})$, with a median value of $23 \mathrm{pg} \mathrm{g}^{-1}(0.5 \mathrm{ng}$ of $\mathrm{Pb})$. The estimated $\mathrm{Pb}$ amount, the ratios obtained and their uncertainties (95\% confidence interval) are reported in Table 2.

At $5 \mathrm{pg} \mathrm{g}^{-1} \mathrm{~Pb}$ concentration, the uncertainty on the ${ }^{207} \mathrm{~Pb} /{ }^{206} \mathrm{~Pb}$ ratio $(n=2)$ was assessed to be $\sim 0.08 \%$. This result is almost a factor of 5 better than that calculated for the data reported by Vallelonga et al. ${ }^{1}(0.39 \%, n=7)$ at $10 \mathrm{pg} \mathrm{g}^{-1}$ of $\mathrm{Pb}$, using ID-TIMS and $10 \mathrm{~g}$ of snow.

In Fig. 3, the data are presented in a three-isotope plot. The $\mathrm{Pb}$ isotope ratios plotted on a straight line and are in agreement with data reported in literature. ${ }^{32}$ Particularly, data lie between the natural and the anthropogenic end-members reported by Van de Velde et al. ${ }^{26}$ and the actual values are similar to those measured at the Hercules Névé for the period 1986-1994. The same authors pointed out that the natural end-member is the result of a mixing of volcanic and crustal inputs, whereas the anthropogenic end-member was governed by both South American and Australian industrial emissions.

Also $\mathrm{Pb}$ isotope ratios measured in the coastal area of East Antarctica $^{33}$ are included in Fig. 3. These values are closer to the

Table 2 Lead isotope ratios measured in the snow collected at Dome C in the 2006 and 2010 campaigns. Uncertainties are reported as $\pm 95 \%$ confidence interval

\begin{tabular}{|c|c|c|c|c|c|c|c|}
\hline Date & $\mathrm{Pb}(\mathrm{ng})$ & ${ }^{207} \mathrm{~Pb} /{ }^{206} \mathrm{~Pb}$ & $\mathrm{U}$ & ${ }^{208} \mathrm{~Pb} /{ }^{206} \mathrm{~Pb}$ & $\mathrm{U}$ & ${ }^{208} \mathrm{~Pb} /{ }^{207} \mathrm{~Pb}$ & $\mathrm{U}$ \\
\hline \multicolumn{8}{|l|}{2006} \\
\hline Dec-05 & 2.5 & 0.8650 & 0.0002 & 2.1048 & 0.0006 & 2.4333 & 0.0008 \\
\hline Feb-06 & - & - & - & - & - & - & - \\
\hline Mar-06 & 0.5 & 0.8685 & 0.0002 & 2.1057 & 0.0005 & 2.4244 & 0.0004 \\
\hline Apr-06 & 0.5 & 0.8747 & 0.0002 & 2.1160 & 0.0005 & 2.4190 & 0.0004 \\
\hline Jul-06 & 0.4 & 0.8629 & 0.0002 & 2.1020 & 0.0008 & 2.4360 & 0.0007 \\
\hline Aug-06 & 0.2 & 0.8455 & 0.0011 & 2.0727 & 0.0016 & 2.4513 & 0.0017 \\
\hline Sep-06 & 0.3 & 0.8542 & 0.0004 & 2.0914 & 0.0007 & 2.4484 & 0.0006 \\
\hline Oct-06 & 1.1 & 0.8445 & 0.0002 & 2.0692 & 0.0005 & 2.4503 & 0.0005 \\
\hline Nov-06 & 0.1 & 0.8469 & 0.0009 & 2.0774 & 0.0014 & 2.4529 & 0.0013 \\
\hline Dec-06 & - & - & - & - & - & - & - \\
\hline Mar-10 & 1.4 & 0.8626 & 0.0002 & 2.0979 & 0.0004 & 2.4321 & 0.0003 \\
\hline Apr-10 & 1.0 & 0.8650 & 0.0002 & 2.1041 & 0.0004 & 2.4324 & 0.0003 \\
\hline May-10 & 14 & 0.8701 & 0.0002 & 2.1108 & 0.0006 & 2.4259 & 0.0007 \\
\hline Jun-10 & 0.4 & 0.8596 & 0.0002 & 2.0939 & 0.0005 & 2.4358 & 0.0005 \\
\hline Jul-10 & 0.6 & 0.8596 & 0.0003 & 2.0945 & 0.0006 & 2.4367 & 0.0007 \\
\hline Aug-10 & 0.2 & 0.8606 & 0.0004 & 2.0969 & 0.0008 & 2.4364 & 0.0008 \\
\hline Sep-10 & 1.3 & 0.8640 & 0.0005 & 2.1006 & 0.0008 & 2.4312 & 0.0012 \\
\hline Oct-10 & 0.3 & 0.8591 & 0.0004 & 2.0956 & 0.0007 & 2.4393 & 0.0007 \\
\hline Nov-10 & 0.1 & 0.8499 & 0.0005 & 2.0799 & 0.0014 & 2.4473 & 0.0019 \\
\hline Dec-10 & 0.4 & 0.8608 & 0.0002 & 2.0974 & 0.0006 & 2.4365 & 0.0006 \\
\hline
\end{tabular}




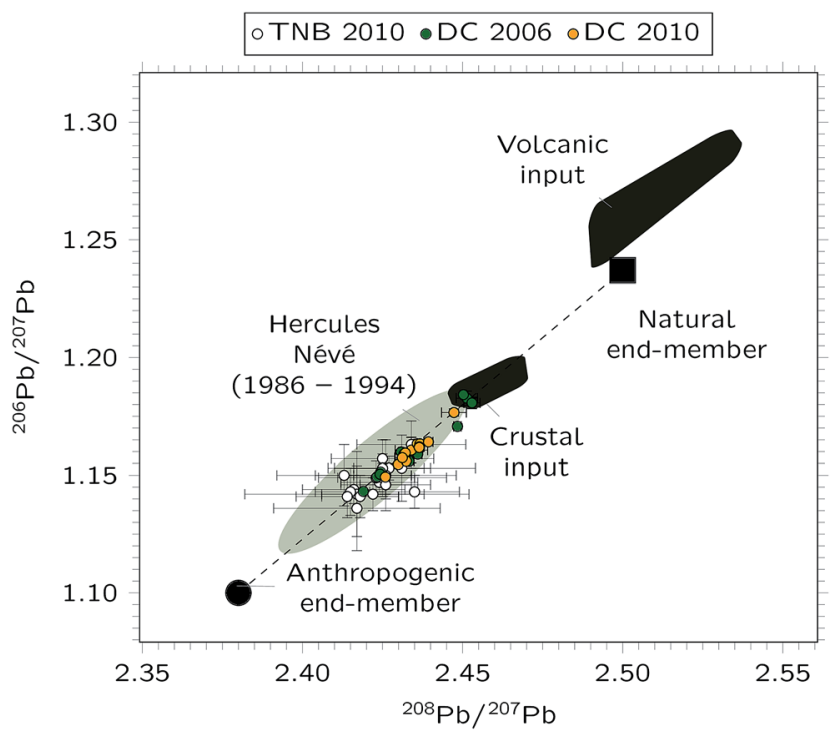

Fig. 3 Three-isotopes plot showing the results obtained for the Antarctic snow samples collected at Dome C during the 2006 (•) and 2010 (๑) campaigns, respectively. For comparison, data from Bazzano et al. ${ }^{33}$ determined in particulate matter from Terra Nova Bay (Coastal Antarctica) are also reported (0), while the shaded areas are from Van de Velde et al. ${ }^{26}$ All the error bars represent $95 \%$ confidence intervals.

anthropogenic end-member than those measured on the Plateau, possibly indicating a larger anthropogenic input for the coastal area.

The time-series obtained for the years 2006 and 2010 are reported in Fig. 4. The first year showed a strong seasonal variation of the ${ }^{208} \mathrm{~Pb} /{ }^{207} \mathrm{~Pb}$ ratio, characterised by lower values from March to July 2006, and higher values from both December 2005 to January 2006, and from September to November 2006. Particularly, the ratios measured during spring showed values similar to those of the pelagic sediments and South Sandwich volcanic rock, ${ }^{26}$ thus suggesting a predominance of crustal $\mathrm{Pb}$ for this period. This result partly contradicts that reported by Burn-Nunes et al., ${ }^{34}$ who found a maximum of both anthropogenic and mineral dust occurring during spring and autumn in the late 1880s. On the other hand, Planchon et $a .^{32}$ reported evidence for close-to-radiogenic values for the

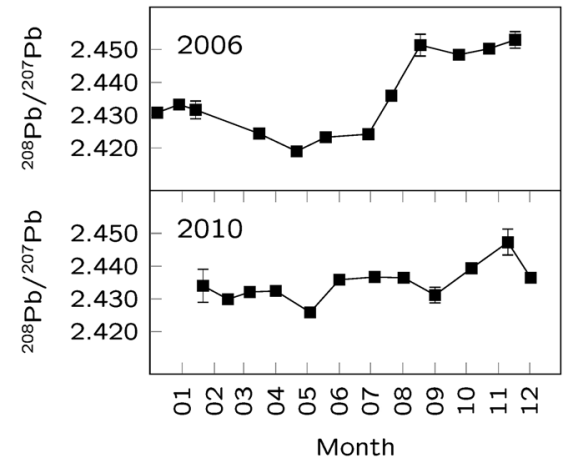

Fig. 4 Annual variation of the ${ }^{208} \mathrm{~Pb} /{ }^{207} \mathrm{~Pb}$ ratio for both the periods considered. Error bars represent $95 \%$ confidence intervals.
${ }^{206} \mathrm{~Pb} /{ }^{207} \mathrm{~Pb}$ ratio occurring in spring/summer during maxima of dust deposition, likely originating from South America.

On the contrary, a clear seasonal trend was not apparent in the $\mathrm{Pb}$ isotope ratios recorded for the 2010 samples, showing just minor fluctuations around the average value $\left({ }^{208} \mathrm{~Pb} /{ }^{207} \mathrm{~Pb}=\right.$ $2.435 \pm 0.005)$. The absence of a regular seasonal pattern was also reported by other authors, suggesting that the transport of aerosols and their deposition on the Antarctic ice sheet are complex and may vary from year to year. ${ }^{26,35}$ To improve the understanding of this variability and to highlight possible correlation with meteorological patterns, the analysis of more years and the use of additional chemical markers is clearly required.

\section{Conclusions}

The method developed allowed for MC-ICP-MS Pb isotopic analysis at concentrations as low as $0.5 \mathrm{ng} \mathrm{mL} \mathrm{m}^{-1}$, using $0.2 \mathrm{~mL}$ of sample solution only. The intermediate precision of the ${ }^{207} \mathrm{~Pb} /{ }^{206} \mathrm{~Pb}$ measurement was $0.11 \%$ RSD $(n=73)$ and $0.31 \%$ $\operatorname{RSD}(n=3)$ at $10 \mathrm{ng} \mathrm{mL}{ }^{-1}$ and $0.5 \mathrm{ng} \mathrm{mL}^{-1}$, respectively.

The small sample consumption allowed us to combine the method with a simple analyte pre-concentration procedure consisting of freeze-drying of $20 \mathrm{~g}$ samples of snow, thus providing accurate ratios at $\mathrm{Pb}$ concentration levels down to $5 \mathrm{pg} \mathrm{g}^{-1}$. The mean concentration of the blanks $(0.5 \pm 0.3 \mathrm{pg}$ $\mathrm{g}^{-1}$ ) was sufficiently low to obtain reliable $\mathrm{Pb}$ isotope ratios in this range of concentrations. Particularly, at $5 \mathrm{pg} \mathrm{g}^{-1}$, the uncertainty associated to the blank subtraction accounted for about $38 \%$ of the total uncertainty budget, thus still not representing the major contribution.

The analytical protocol developed was applied to the measurement of $\mathrm{Pb}$ isotope ratios in recent snow samples collected at Dome C (Antarctic Plateau) during the 2006 and 2010 campaigns. These are the first data of $\mathrm{Pb}$ isotope ratios measured in the Antarctic snow using MC-ICP-MS. The relative uncertainty of the ratios measured at $5 \mathrm{pg} \mathrm{g}^{-1}$ turned out to be competitive with that reported in literature for ID-TIMS. Moreover, the data provided some preliminary insights into the complex pattern of the transport of $\mathrm{Pb}$ towards Antarctica and its deposition on the ice sheet.

\section{Acknowledgements}

This study was partially founded by the Italian National Program for Research in Antarctica (Project 2013/AZ3.04). Thanks to Harry Vandeput for his assistance with the hardware and Dr Paolo Grigioni for the help with meteorological data.

\section{References}

1 P. Vallelonga, P. Gabrielli, E. Balliana, A. Wegner, B. Delmonte, C. Turetta, G. Burton, F. Vanhaecke, K. J. R. Rosman, S. Hong, C. F. Boutron, P. Cescon and C. Barbante, Quat. Sci. Rev., 2010, 29, 247-255.

2 P. Vallelonga, P. Gabrielli, K. J. R. Rosman, C. Barbante and C. F. Boutron, Geophys. Res. Lett., 2005, 32, 1-4. 
3 K. J. R. Rosman, W. Chisholm, C. F. Boutron, J.-P. Candelone, J.-L. Jaffrezo and C. I. Davidson, Earth Planet. Sci. Lett., 1998, 160, 383-389.

4 K. J. R. Rosman, W. Chisholm, C. F. Boutron, J.-P. Candelone and C. C. Patterson, Geophys. Res. Lett., 1994, 21, 2669-2672.

5 W. Chisholm, K. J. R. Rosman, C. F. Boutron, J. P. Candelone and S. Hong, Anal. Chim. Acta, 1995, 311, 141-151.

6 P. Vallelonga, K. Van de Velde, J. P. Candelone, C. Ly, K. J. R. Rosman, C. F. Boutron, V. I. Morgan and D. J. Mackey, Anal. Chim. Acta, 2002, 453, 1-12.

7 L. Balcaen, L. Moens and F. Vanhaecke, Spectrochim. Acta, Part B, 2010, 65, 769-786.

8 J. L. Todolì and J. M. Mermet, J. Anal. At. Spectrom., 2002, 17, 913-921.

9 J.-L. Todoli and J.-M. Mermet, J. Anal. At. Spectrom., 2002, 17, 345-351.

10 C. Lagomarsino, M. Grotti, J. L. Todoli and J. M. Mermet, J. Anal. At. Spectrom., 2007, 22, 523.

11 F. Ardini, M. Grotti, R. Sánchez and J. L. Todolí, J. Anal. At. Spectrom., 2012, 27, 1400-1404.

12 M. Grotti, F. Ardini and J. L. Todoli, Anal. Chim. Acta, 2013, 767, 14-20.

13 E. Paredes, M. Grotti, J. M. Mermet and J. L. Todolí, J. Anal. At. Spectrom., 2009, 24, 903.

14 E. Paredes, D. G. Asfaha, E. Ponzevera, C. Brach-Papa, M. Van Bocxstaele, J. L. Todolì and C. R. Quetel, J. Anal. At. Spectrom., 2011, 26, 1372-1379.

15 E. Paredes, D. G. Asfaha and C. R. Quétel, J. Anal. At. Spectrom., 2013, 28, 320-326.

16 E. Paredes, J. L. Todoli and C. R. Quétel, J. Anal. At. Spectrom., 2013, 28, 327-333.

17 A. Bazzano and M. Grotti, J. Anal. At. Spectrom., 2014, 29, 926-933.

18 J. Woodhead, J. Anal. At. Spectrom., 2002, 17, 1381-1385.

19 D. C. Baxter, I. Rodushkin, E. Engström and D. Malinovsky, J. Anal. At. Spectrom., 2006, 21, 427.
20 M. Grotti, F. Soggia and J. Luis Todoli, Analyst, 2008, 133, 1388-1394.

21 A. Cocherie and M. Robert, Chem. Geol., 2007, 243, 90-104.

22 T. Kuritani and E. Nakamura, Chem. Geol., 2002, 186, 31-43.

23 Y. Amelin and W. J. Davis, J. Anal. At. Spectrom., 2006, 21, 1053.

24 A. Makishima and E. Nakamura, J. Anal. At. Spectrom., 2010, 25, 1712.

25 M. F. Thirlwall, Chem. Geol., 2002, 184, 255-279.

26 K. Van de Velde, P. Vallelonga, J.-P. Candelone, K. J. R. Rosman, V. Gaspari, G. Cozzi, C. Barbante, R. Udisti, P. Cescon and C. F. Boutron, Earth Planet. Sci. Lett., 2005, 232, 95-108.

27 BIPM, IEC, IFCC, ISO, IUPAC, IUPAP and OIML, Guide to the expression of uncertainty in measurement, 2nd edn, 1995.

28 R. N. Taylor, O. Ishizuka, A. Michalik, J. A. Milton and I. W. Croudace, J. Anal. At. Spectrom., 2014, 30, 198-213.

29 J. Baker, D. Peate, T. Waight and C. Meyzen, Chem. Geol., 2004, 211, 275-303.

30 M. Grotti, F. Soggia, F. Ardini, E. Magi, S. Becagli, R. Traversi and R. Udisti, Chemosphere, 2015, DOI: 10.1016/ j.chemosphere.2014.10.094, in press.

31 R. Udisti, S. Becagli, S. Benassai, E. Castellano, I. Fattori, M. Innocenti, A. Migliori and R. Traversi, Ann. Glaciol., 2004, 39, 53-61.

32 F. A. M. Planchon, K. Van de Velde, K. J. R. Rosman, E. W. Wolff, C. P. Ferrari and C. F. Boutron, Geochim. Cosmochim. Acta, 2003, 67, 693-708.

33 A. Bazzano, F. Soggia and M. Grotti, Environ. Chem., 2015, DOI: $10.1071 /$ en14185, in press.

34 L. J. Burn-Nunes, P. Vallelonga, R. D. Loss, G. R. Burton, A. Moy, M. Curran, S. Hong, A. M. Smith, R. Edwards, V. I. Morgan and K. J. R. Rosman, Geochim. Cosmochim. Acta, 2011, 75, 1-20.

35 F. A. M. Planchon, C. F. Boutron, C. Barbante, G. Cozzi, V. Gaspari, E. W. Wolff, C. P. Ferrari and P. Cescon, Sci. Total Environ., 2002, 300, 129-142. 